\title{
Modelling of High Pressure, High Concentration Carbon Dioxide Capture in Absorption Column
}

\author{
Tan Lian See ${ }^{a}$, Tay Wee Horng ${ }^{b}$, Lau Kok Keong ${ }^{c}$ and Azmi M Shariff ${ }^{d *}$ \\ Research Centre for $\mathrm{CO}_{2}$ Capture $\left(\mathrm{RCCO}_{2} \mathrm{C}\right)$, Universiti Teknologi PETRONAS,
}

31750 Tronoh, Perak, Malaysia

atan.liansee@gmail.com, btay2832@gmail.com, 'laukokkeong@petronas.com.my, dazmish@petronas.com.my

Keywords: Mass transfer, countercurrent packed column, $\mathrm{CO}_{2}$ absorption, high pressure.

\begin{abstract}
With the depletion of low carbon dioxide $\left(\mathrm{CO}_{2}\right)$ content natural gas reserves, there is a pressing need to explore the vastly undeveloped high $\mathrm{CO}_{2}$ content natural gas reserves and reduce the release of greenhouse gas $\mathrm{CO}_{2}$ into environment. Our previous investigation on the absorption performance of $\mathrm{CO}_{2}$ at high concentration level of $50 \%$ from mixture of $\mathrm{CO}_{2}$-natural gas stream for 20wt\% monoethanolamine (MEA) solution in countercurrent packed column indicated efficient removal at high pressure condition. In this present work, a combination mass transfer, chemical reaction of MEA as well as mass conservation equation was developed to model the removal behavior of the high pressure, high concentration $\mathrm{CO}_{2}$ capture along the absorption column. The model developed in this study had satisfactorily represented the mass transfer behavior for high pressure and high $\mathrm{CO}_{2}$ concentration gas removal along the absorption column.
\end{abstract}

\section{Introduction}

Natural gas is known to be the cleanest and most hydrogen-rich of all the hydrocarbon energy sources with high energy conversion efficiencies for power generation [1]. However, the existing low carbon dioxide $\left(\mathrm{CO}_{2}\right)$ natural gas reserves are depleting fast. In order to support the continuous increasing demand for energy worldwide [2], there is an urgent need to explore the vastly undeveloped natural gas reserves with high $\mathrm{CO}_{2}$ content up to $80 \%$ [3]. Absorption of $\mathrm{CO}_{2}$ for natural gas purification has been in place in the industry for decades [4]. Research on $\mathrm{CO}_{2}$ capture from flue gas is also being conducted rigorously worldwide in effort to reduce the catastrophic global warming effect [3]. Nevertheless, the existing system/research mainly focused on low $\mathrm{CO}_{2}$ concentration up to $20 \%$ [5]. Hence, in order to move forward with the implementation of purification process for high $\mathrm{CO}_{2}$ content natural gas, it is of utmost importance to have an understanding of the mass transfer performance under continuous flow process at high $\mathrm{CO}_{2}$ content and high pressure condition.

Our previous investigation on the absorption performance of $\mathrm{CO}_{2}$ at high concentration level of $50 \%$ from mixture of $\mathrm{CO}_{2}$-natural gas stream at high pressure condition for $20 \mathrm{wt} \%$ monoethanolamine (MEA) aqueous solution in countercurrent packed column indicated efficient removal at higher pressure [6]. In order to simulate and predict the $\mathrm{CO}_{2}$ removal behavior in counter current absorption column, several models with constant gas flow rate assumption had been previously developed by other researchers $[7,8]$. However, in the case of high concentration $\mathrm{CO}_{2}$ capture conducted in our work, the reduction of the total flow rate of vapor was significant along the column. As such, this current work aims to develop a model applicable for high pressure and high concentration $\mathrm{CO}_{2}$ capture along the absorption column. A combination of mass transfer, chemical reaction of MEA as well as mass conservation equation model was utilized to develop and elucidate the transport of the conserved mass along the column with the significant reduction of total gas flow rate along the column from high concentration of $\mathrm{CO}_{2}$ at inlet point to low concentration of $\mathrm{CO}_{2}$ at gas outlet. The predicted trend of absorption performance at high pressure and high concentration of $\mathrm{CO}_{2}$ using the developed model was then compared with the actual experimental results for model validation. 


\section{Theory and background}

Model. $\mathrm{A} \mathrm{CO}_{2}$ absorption model for the countercurrent packed column was developed based on the mass conservation of liquid and gas (vapor) phases. Several assumptions were made for the model, including : (i) Gas conservation was in steady-state, (ii) pressure drop was not significant along the column, (iii) the density and flow rate of the liquid was constant and (iv) the temperature was constant along the column.

Along the absorption column, the amount of the initially high $\mathrm{CO}_{2}$ concentration in gas stream that was absorbed in liquid/solvent reduced the flow rate of the total gas volume along the column at constant pressure. Hence, a model which considers the significant reduction of the total gas flow rate needs to be developed to predict the performance of the high pressure and high $\mathrm{CO}_{2}$ concentration absorption column. The correlation of axial velocity with the $\mathrm{CO}_{2}$ absorption rate can be obtained by mass conservation equation. One dimensional total mole conservation of the $\mathrm{CO}_{2}$ gas phase in steady state can be expressed in Eq. 1:

$$
x_{v} \frac{d\left(C u_{v}\right)}{d z}=x_{v} \frac{C d\left(u_{v}\right)}{d z}=-N_{C O 2}
$$

where, $C$ is the total mole concentration of gas phase, $N_{C O 2}$ is the source term in one unit space meter cube representing the $\mathrm{CO}_{2}$ mole absorption rate $\left(\mathrm{kg}\right.$ mole s$\left.^{-1} \mathrm{~m}^{-3}\right), x_{v}$ is the gas volume fraction in space column and $u_{v}$ is the gas phase velocity in the $\mathrm{z}$ direction (along the column height). For constant total pressure and high concentration $\mathrm{CO}_{2}$, the correlation of gas flow rate with the $\mathrm{CO}_{2}$ mole transfer with distance is expressed as in Eq. 2:

$$
x_{v} \frac{d\left(C_{\mathrm{CO} 2}\right)}{d z}=-\frac{N_{\mathrm{CO} 2}}{u_{v}}\left(1-y_{\mathrm{CO} 2}\right)
$$

where, $y_{\mathrm{CO} 2}$ is the $\mathrm{CO}_{2}$ mole fraction in gas phase and $C_{\mathrm{CO} 2}$ is the mole concentration in gas phase $(\mathrm{kg}$ mole $\left.\mathrm{m}^{-3}\right)$. Equation 2 includes the factor $\left(1-y_{\mathrm{CO} 2}\right)$, as the pressure was assumed to be constant, which is different from the other model with the constant flow rate assumption [7]. $N_{\mathrm{CO} 2}$ in one unit space meter cube is functioned by the overall coefficients and partial pressure of $\mathrm{CO}_{2}$, as expressed in Eq. 3:

$$
N_{\mathrm{CO} 2}=K_{G} a_{\mathrm{eff}}\left(p_{\mathrm{CO} 2}-p_{e, \mathrm{CO} 2}\right)
$$

where, $K_{G}$ is the overall mass transfer coefficient $\left(\mathrm{kgmol} \mathrm{m}^{-2} \mathrm{~s}^{-1} \mathrm{kPa}^{-1}\right), a_{\text {eff }}$ is the effective surface area of liquid and gas phase in one unit space meter cube $\left(\mathrm{m}^{-1}\right), p_{C O 2}$ is the $\mathrm{CO}_{2}$ partial pressure $(\mathrm{kPa})$ and $p_{e, C O 2}$ is the $\mathrm{CO}_{2}$ partial pressure in equilibrium condition $(\mathrm{kPa})$. The overall mass transfer coefficient that considered MEA enhancement can be obtained based on liquid and gas phase mass transfer coefficient, as expressed in Eq. 4:

$$
\frac{1}{K_{G}}=\frac{\left(1-y_{C O 2}\right)}{k_{g}}+\frac{H_{C O 2}}{k_{l}^{O} E}
$$

where, $k_{g}$ is the gas mass transfer coefficient $\left(\mathrm{kgmol} \mathrm{m}^{-2} \mathrm{~s}^{-1} \mathrm{kPa}^{-1}\right), k_{l}^{o}$ is the liquid mass transfer coefficient, $E$ is the enhancement factor, $H_{\mathrm{CO}_{2}}$ is Henry's constant $\left(\mathrm{kPa} \mathrm{kgmol}^{-1} \mathrm{~m}^{3}\right) \cdot \frac{1}{\left(1-y_{\mathrm{CO} 2}\right)}$ was introduced in the gas mass transfer coefficient by assuming that methane $\left(\mathrm{CH}_{4}\right)$ was not absorbed by the solvent. The enhancement factor of MEA solvent can be determined using the approximate solutions provided by Pintola et al (1993) [9], as expressed in Eq. 5:

$$
E=1+\frac{1}{\left[\left(\frac{1}{E_{\infty}-1}\right)^{1.35}+\left(\frac{1}{E_{1}-1}\right)^{1.35}\right]^{\frac{1}{1.35}}}
$$


where,

$E_{\infty}=1+\frac{C_{M E A} D_{M E A}}{b D_{C O 2} C_{C O 2 i}}, \quad E_{1}=\frac{\sqrt{M}}{\tanh \sqrt{M}}, \quad M^{2}=\frac{D_{C O 2} k_{2} C_{M E A}}{k_{l}^{o^{2}}}$

$C_{M E A}$ is the MEA concentration in solvent, $C_{C O 2 i}$ is the $\mathrm{CO}_{2}$ mole concentration $\left(\mathrm{kg}\right.$ mole $\left.\mathrm{m}^{-3}\right)$ in liquid and vapor interface, $k_{2}$ is the rate constant of overall MEA and $\mathrm{CO}_{2}$ reaction given by Hikita et al (1977) [10], b is the stoichiometric factor of MEA reaction and $D_{M E A}$ and $D_{C O 2}$ are the diffusivity of MEA and $\mathrm{CO}_{2}$ in liquid $\left(\mathrm{m}^{2} \mathrm{~s}^{-1}\right)$. The gas mass transfer coefficients were calculated using the correlation function of Onda et al (1968) [11], which is expressed in Eq. 6:

$$
k_{g}=C_{1} \frac{a_{v} D_{v}}{R T}\left(\frac{G}{a_{v} \mu_{v}}\right)^{0.7}\left(\frac{\mu_{v}}{\rho_{v} D_{v}}\right)^{0.33}\left(a_{v} d p\right)^{-2}
$$

where, $C_{1}$ is the corrected factor, $D_{v}$ is diffusivity of vapor $\left(\mathrm{m}^{2} \mathrm{~s}^{-1}\right), \mu_{v}$ is gas viscosity $\left(\mathrm{kg} \mathrm{m}^{-1} \mathrm{~s}^{-1}\right), a_{v}$ is dry packing area per unit volume $\left(\mathrm{m}^{-1}\right), \rho_{v}$ is mass density of gas $\left(\mathrm{kg} \mathrm{m}^{-3}\right)$, and $d p$ is nominal diameter of a piece of packing $(\mathrm{m})$. Meanwhile, the liquid mass transfer coefficient is validated by fitting the experimental results with the simulated results. For liquid phase, the unsteady state one dimensional conservation of liquid flow was introduced to predict the variation of $\mathrm{CO}_{2}$ and MEA concentration in liquid, as stated in Eq. 7:

$$
\frac{d\left(C_{C O 2}^{l}\right)}{d t}+\frac{u_{l} d\left(C_{C O 2}^{l}\right)}{d z}=\frac{N_{C O 2}}{1-x_{v}}
$$

where, $u_{l}$ is the liquid phase velocity $\left(\mathrm{m} \mathrm{s}^{-1}\right)$ in the $\mathrm{z}$ direction (along the column height) and $C_{\mathrm{CO} 2}^{l}$ is the mole concentration of $\mathrm{CO}_{2}$ in liquid phase $\left(\mathrm{kg}\right.$ mole $\left.\mathrm{m}^{-3}\right)$. Meanwhile, the mole concentration of

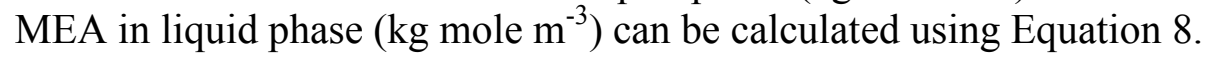

$$
C_{M E A}^{l}=C_{M E A}^{l}-b C_{C O 2}^{l}
$$

Numerical method. The $\mathrm{CO}_{2}$ absorption model was executed using Matlab code. In the numerical model, the countercurrent absorption column was divided into an infinite cell with a distance $\Delta z$ from the bottom to the top of the column as shown in Fig. 1 (a). The mass conservation equation of each cell was solved from the bottom to the top of the column. The vapor mass conservation was assumed to be in the steady state. The iteration time calculations were performed until the liquid steady state solution was achieved. The increasing of the $\mathrm{CO}_{2}$ concentration for liquid phase with an iteration time can be calculated through the mass transfer rate from the gas steady state conservation equation. The liquid mass transfer coefficient was assumed to be constant under different pressure.

\section{Experiment Methodology}

Materials. Monoethanolamine (MEA) (99\%) used in this study were purchased from Acros Organics. Distilled water was used to prepare the aqueous solvent for this work. $\mathrm{CO}_{2}(99.9 \%)$ used in this experiment was purchased from Air Product Malaysia while natural gas with $97 \%$ of $\mathrm{CH}_{4}$ and $2 \%$ of $\mathrm{CO}_{2}$ was supplied by Petronas Dagangan Bhd.

Methodology for absorption experiment. The experiments were performed using a pilot scale experimental set up as shown in Fig. 1 (b). The absorption column inner diameter (ID) was $0.145 \mathrm{~m}$ with column height of $1.769 \mathrm{~m}$. The packing used in this study was structured packing FLEXIPAC $1 \mathrm{Y}$ by Koch-Glitsch. There was a distance of $0.5 \mathrm{~m}$ between the packing and liquid distributor.

The absorption performance experiment was started by introducing a gas mixture from gas supply system to the bottom of the absorption column. The concentration of $\mathrm{CO}_{2}$ in $\mathrm{CO}_{2}$ and natural gas feed gas mixture was adjusted through mass flow controller. A back pressure regulator in the system would maintain the pressure of column at the desired level. Liquid feed at $1 \mathrm{Litre} / \mathrm{min}$ was then 
pumped to the top of the column from a 200-litre feed tank to create counter-current contact between gas and liquid. The absorption process was operated until steady state condition was achieved.

The $\mathrm{CO}_{2}$ concentration in the feed gas and treated gas from the start of experiment until it reached steady state was measured using $\mathrm{CO}_{2}$ infrared (IR) gas analyzer model ZRJF4Y25 (Fuji Electric Instruments).

(a)

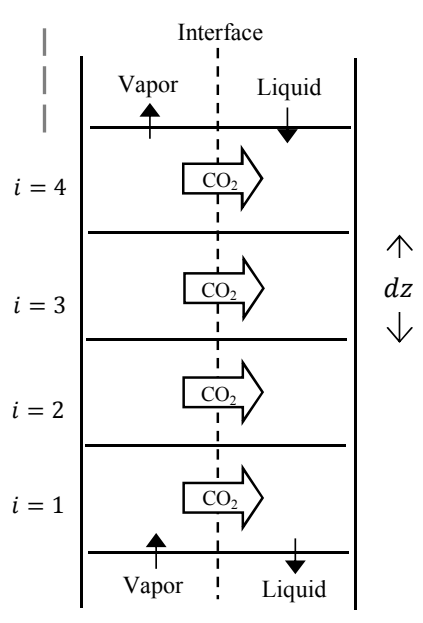

(b)

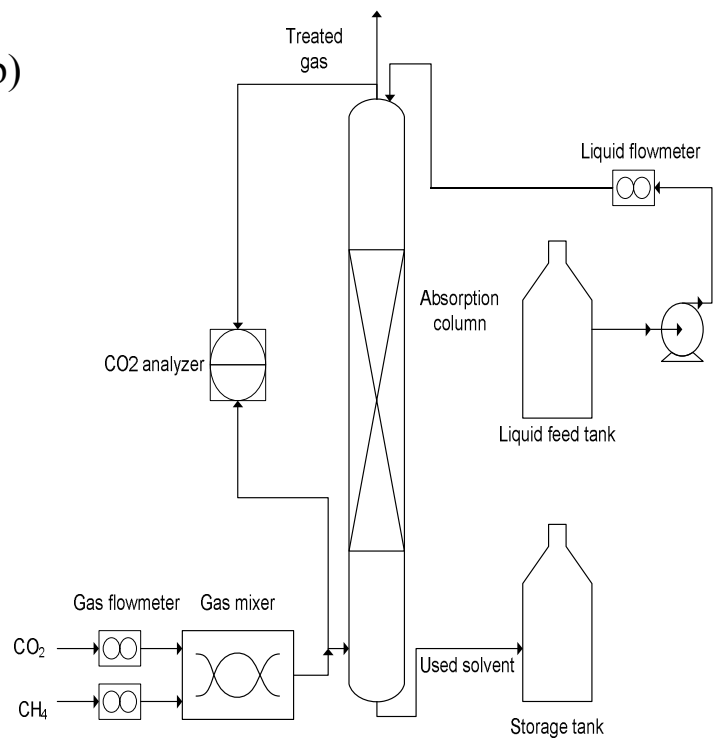

Fig. 1: a) Schematic of the countercurrent absorption column with an infinite cell for mass conservation equation. b) Schematic diagram of experimental setup.

\section{Results \& Discussions}

Fig. 2 shows the comparison between the simulated results and experimental results of $\mathrm{CO}_{2}$ removal along the absorption column at 10 bar and 30 bar. The higher pressure condition produced a better efficiency of the mass transfer of $\mathrm{CO}_{2}$ from gas to the solvent. Fresh solvent was introduced at the top of the column and the simulated results for MEA concentration indicated that at a fixed MEA total mole flow rate, shorter absorption column would be required when the pressure condition was higher.

(a)

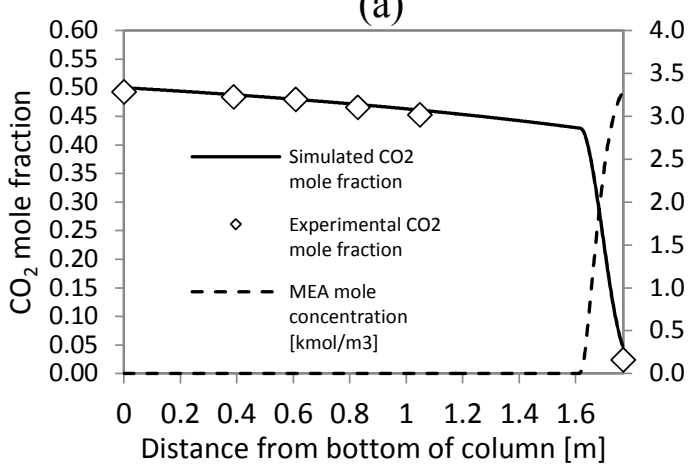

(b)

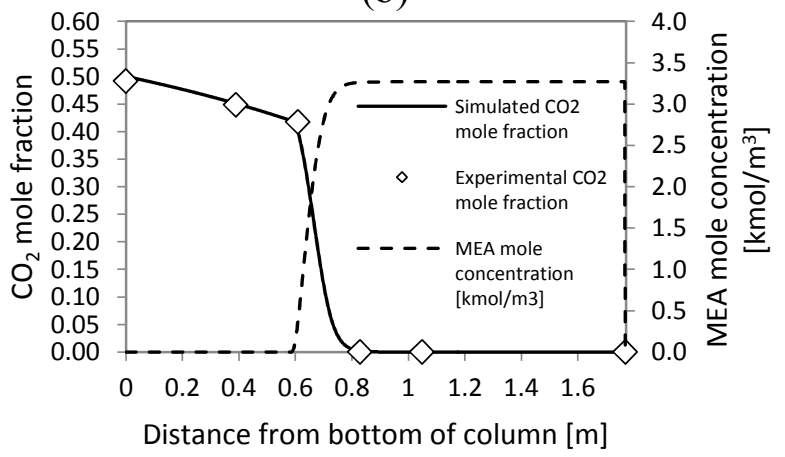

Fig. 2: The comparison between the simulated results and experimental results of 10 bar operating pressure (a) and 30 bar operating pressure (b).

Fig 3 shows that the maximum overall mass transfer rate is allocated at top of the column of 10 bar and middle of column of $30 \mathrm{bar}$. The results indicated that higher pressure condition enhanced the efficiency of the mass transfer of $\mathrm{CO}_{2}$ from gas to the solvent. This was due to the increased physical absorption with higher gas pressure as the physical solubility of $\mathrm{CO}_{2}$ into the solvent was significantly affected by the gas pressure. The simulated results based on the developed model were found to be in good agreement with the experimental results. 

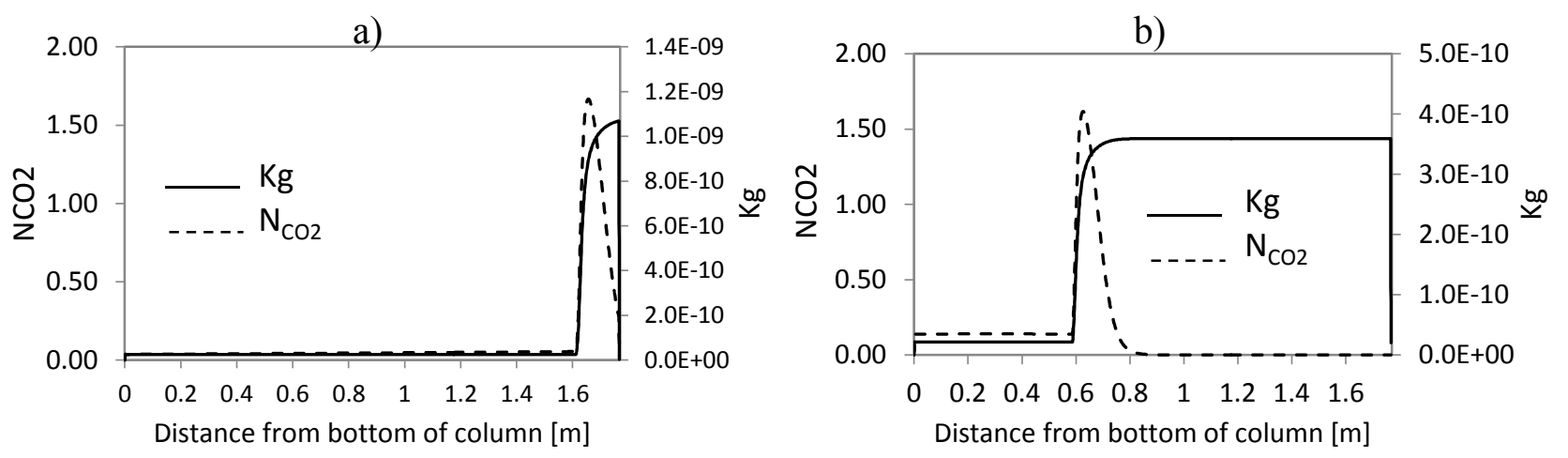

Fig. 3: The simulated overall mass transfer, $\mathrm{Kg}$ and mole source term in one unit volume, $\mathrm{N}_{\mathrm{CO} 2}$ of 10 bar operating pressure (a) and 30 bar operating pressure (b).

\section{Conclusion}

As a conclusion, the inclusion of the unsteady state liquid mass conservation equation into the model development was crucial in order to elucidate the transport and the absorption of MEA along the column for high $\mathrm{CO}_{2}$ concentration in feed gas and operating at high pressure absorption column. Since the total gas flow rate was correlated with the total $\mathrm{CO}_{2}$ transfer flowing through a certain column distance, the effect of the reduction of total gas flow rate along the column is essential to be implemented for the case of high concentration of $\mathrm{CO}_{2}$ at inlet point to low concentration of $\mathrm{CO}_{2}$ at gas outlet. Based on the modelling results, the increased $\mathrm{CO}_{2}$ loading in MEA solution at the bottom of column significantly reduced the $\mathrm{CO}_{2}$ absorption at the region. High pressure condition is also found to enhance the efficiency of the mass transfer of $\mathrm{CO}_{2}$ from gas to the solvent.

\section{References}

[1] M. J. Economides and D. A. Wood, The state of natural gas, Journal of Natural Gas Science and Engineering. 1 (2009) 1-13.

[2] IEA, CO2 Emissions from Fuel Combustion. France: OCDE/IEA, (2008)

[3] L. S. Tan, et al., Factors affecting $\mathrm{CO} 2$ absorption efficiency in packed column: A review, Journal of Industrial and Engineering Chemistry, (2012)

[4] A. L. Kohl and R. B. Nielsen, Gas Purification, 5th ed. Texas: Gulf Publishing Company, 1997.

[5] H. Yang, et al., Progress in carbon dioxide separation and capture: A review, Journal of Environmental Sciences, 20 (2008) 14-27.

[6] L. S. Tan, et al., Impact of High Pressure on High Concentration Carbon Dioxide Capture from Natural Gas by Monoethanolamine/N-Methyl-2-Pyrrolidone Solvent in Absorption Packed Column, submitted to International Journal of Greenhouse Gas Control, (2014)

[7] F. M. Khan, et al., Modelling reactive absorption of $\mathrm{CO} 2$ in packed columns for post-combustion carbon capture applications," Chemical Engineering Research and Design, 89 (2011) 1600-1608.

[8] T. Sema, et al., Comprehensive mass transfer and reaction kinetics studies of a novel reactive 4-diethylamino-2-butanol solvent for capturing CO2" Chemical Engineering Science, 100 (2013) 183-194.

[9] T. Pintola, et al., Simulation of pilot plant and industrial CO2-MEA absorbers, Gas Separation \& Purification, 7 (1) (1993) 47-52.

[10] H. Hikita, et al., The kinetics of reactions of $\mathrm{CO} 2$ with MEA, DEA and TEA by a rapid mixing method, Chemical Engineering Journal, 13 (1977) 7-12.

[11] K. Onda, et al., Mass transfer coefficients between gas and liquid phases in packed column. Journal of Chemical Engineering of Japan, 1 (1) (1968) 56-61. 